\title{
Formação profissional e futuro: expectativas dos adolescentes aprendizes
}

\section{Professional training and future: expectations of adolescent apprentices}

\author{
Orlando Júnior Viana MACÊDO \\ Maria de Fátima Pereira ALBERTO \\ Anísio José da Silva ARAUJO
}

\begin{abstract}
Resumo
Neste artigo discute-se o que os adolescentes aprendizes esperam do futuro. Participaram do estudo 16 sujeitos, de 14 a 18 anos, tanto do sexo masculino quanto feminino, do curso de Serviços Administrativos do Serviço Nacional de Aprendizagem do Comércio. Recorreu-se à metodologia qualitativa com entrevistas semiestruturadas, individuais e coletivas. Os dados foram analisados por meio da técnica de análise temática. As falas denotaram que adolescentes almejam profissões de nível superior e mesmo de nível médio e que o Programa pode ajudá-los a realizar tais expectativas, pela experiência e disciplinamento. Percebe-se uma subjetividade engendrada como resíduo, no processo de produção de uma sociedade modelada sob a lógica do capital, de forma que os sujeitos, ao serem adestrados ao mundo do trabalho, parecem não conseguir ressignificar seus sonhos e desejos, nem perceber que estes se constituem, também, na relação com o mundo social, assim escamoteando as causas estruturais de seu sucesso ou fracasso.
\end{abstract}

Unitermos: Aprendizagem. Expectativa de futuro. Formação profissional.

\begin{abstract}
In this article, adolescent apprentices' expectations for the future were discussed. The study included 16 subjects aged 14 to 18 years old, both male and female, from Serviço Nacional de Aprendizagem do Comércio Administrative Services course. A qualitative methodology including individual and collective semi-structured interviews was used. Thematic analysis technique was used to analyze data. The speeches show that the adolescents yearn for higher education professions as well high school professions, and that the program can help them to achieve such expectations through experience and discipline. Their subjectivity is seen as a residue of the production process of a society, modeled under the logic of capital, so that when they are trained for the world of work, the subjects seem to be incapable of assigning a new meaning to their dreams and wishes; and they do not perceive that these also form part of the relationship with the social world, thus concealing the structural causes of their success and failure.
\end{abstract}

Uniterms: Learning. Future expectations. Professional development.

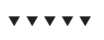

1 Universidade Federal da Paraíba, Centro de Ciências Humanas Letras e Artes, Departamento de Psicologia. Cidade Universitária, Castelo Branco, 58059-900, João Pessoa, PB, Brasil. Correspondência para/Correspondence to: O.J.V. MACÊDO. E-mail: <orlandojrvm@yahoo.com.br>.

Artigo elaborado a partir da dissertação de O.J.V. MACÊDO, intitulada "O sentido da formação profissional e as expectativas de futuro dos adolescentes aprendizes". Universidade Federal da Paraíba, 2006. Apoio: Conselho Nacional de Desenvolvimento Científico e Tecnológico. 
Este artigo versa sobre expectativas de futuro dos adolescentes aprendizes. A condição de aprendizagem define-se como aquela em que o adolescente se profissionaliza trabalhando, dentro de um processo educacional previsto em lei. Compreende uma diversidade de cursos que têm por objetivo propiciar um conhecimento teórico-prático acerca de determinado ofício, cujo exercício exige uma pré-qualificação.

Levando em consideração os aspectos legais, o Programa em questão mostra uma preocupação com o desenvolvimento físico, psíquico, moral e social dos adolescentes. Além disso, procura compatibilizar o trabalho com as especificidades dessa fase de desenvolvimento, e o curso teórico com a parte prática vivenciada nas empresas.

Os cursos teóricos são ministrados por entidades do chamado Sistema S, que envolve diversas entidades: Serviço Nacional de Aprendizagem Rural (SENAR); Serviço Nacional de Aprendizagem do Comércio (SENAC); Serviço Social do Comércio (SESC); Serviço Nacional de Aprendizagem Industrial (SENAI); Serviço Social da Indústria (SESI); Serviço Social de Transporte (SEST); e Serviço Nacional de Aprendizagem do Transporte (SENAT). No caso desta pesquisa, trata-se do curso de Serviços Administrativos oferecido pelo SENAC de João Pessoa.

O Programa de Aprendizagem do Governo Federal évoltado a adolescentes e jovens oriundos de famílias "carentes". Essa caracterização está expressa na Cartilha de Aprendizagem elaborada pelo SENAC, com participação da Superintendência Regional do Trabalho e Emprego do Estado da Paraíba (SRTE/PB). O Programa tem por finalidade facilitar a entrada dos adolescentes no mercado formal de trabalho, por meio da oferta de qualificação profissional condizente com suas expectativas de construírem uma vida pessoal, social e profissional digna e produtiva.

Embora o Programa fosse inicialmente voltado para adolescentes, a Medida Provisória no 251 (Brasil, 2005) deu nova redação ao Art. 428 da Consolidação das Leis do Trabalho (CLT), alterando a idade de participação em programas de aprendizagem - de 14 a 18 anos, para 14 a 24 anos - e modificando o nome do programa para"Jovem Aprendiz".

Ao alterar o foco de formação, a lei amplia a 780 concepção de juventude, estendendo-a até os 24 anos de idade. Dentre outras análises, pode-se entender que a lei homogeneiza os diferentes significados de formação que se dão ao longo dessa ampla faixa etária. Embora essa faixa etária abranja dimensões objetivas e subjetivas que contemplam aspectos diferenciados, a lei uniformiza as diferenças e as desconsidera, numa tônica já presente para os jovens da classe baixa, fazendo construírem-se novas representações. Assim, como observam Sposito e Corrochano (2005), as ações e programas públicos não apenas sofrem os efeitos de determinadas concepções, mas podem agir ativamente na produção de novas representações.

Neste artigo, a definição de adolescência respalda-se na compreensão da psicologia sócio-histórica, que parte do pressuposto de que a adolescência, enquanto categoria de análise, só encontra sentido se inserida na dinâmica histórica, política e cultural de cada sociedade. Deixa, assim, de ser vista como uma fase natural do desenvolvimento, passando a ser considerada como uma fase de desenvolvimento na sociedade moderna ocidental. Uma vez que ela não é universal dos seres humanos, é histórica, como o afirmam Bocke Liebesny (2007). A adolescência, vista sob essa perspectiva, deixa de ser analisada como algo natural, linear e universal, e passa a ser referida a um determinado contexto espacial, temporal e social.

Algumas categorias teóricas são utilizadas por diferentes autores para qualificar a preocupação que os adolescentes apresentam em relação ao futuro, tais como: perspectiva de futuro (Carvalho, Pocinho \& Silva, 2010; Locatelli, Bzuneck \& Guimarães, 2007); projeto de vida (Aguiar \& Ozella, 2003; Bock \& Liebesny, 2003; Da Silva, 2011; Lima, 2006; Wagner, Falcke \& Meza, 1997); plano de vida e planejamento de futuro (Wickert, 2006); expectativas de futuro (Aguiar \& Conceição, 2009; Alberto, 2007; Cassab, 2001; Costa \& Guedes, 2009; Jacobina \& Costa, 2007; Matheus, 2003); expectativas em relação ao futuro profissional e projeto profissional (D'Avila, Krawulski, Veriguine \& Soares, 2011); interesse profissional (Nunes \& Noronha, 2011; Sartori, Noronha \& Nunes, 2009).

Uma vez que não foram constatadas diferenças significativas nas conceituações utilizadas por esses autores para tratarem do que os adolescentes esperam do futuro, elas serão utilizadas neste artigo como se fossem equivalentes, preferindo-se, entretanto, utilizar a denominação "expectativas em relação ao futuro". 
Por expectativas em relação ao futuro compreende-se aquilo que os adolescentes percebem em relação a suas chances futuras, especialmente o lugar do trabalho em seu projeto de vida. Bock e Liebesny (2003) chamam atenção paro o fato de que, embora se refiram ao futuro, é no presente que os projetos de vida são construídos e constituídos, estando eles relacionados à construção da identidade - processo contínuo, fruto de sua pertinência a um grupo social em que concretiza as relações de produção de si mesmo e da realidade na qual se insere. Nesse sentido, as expectativas de futuro contêm as possibilidades criadas em tais relações.

De acordo com Alberto (2007), o futuro, para os trabalhadores precoces, é pensado como uma imagem de trabalho, que pode ser tanto negativa quanto positiva. Seu estudo sobre o trabalho de crianças e adolescentes no setor informal urbano revela que, no caso das expectativas de futuro, há dois aspectos a destacar: uma expectativa de futuro que é da ordem do desejo, e outra que é da ordem da realidade. A primeira revela a aspiração a um futuro melhor por meio do estudo (formar-se e ter um emprego regular que possibilite reconhecimento), enquanto a segunda não enxerga futuro a partir da inserção precoce no trabalho.

Bock e Liebsny (2003), em estudo com adolescentes que cursavam desde a $8^{a}$ série do Ensino Fundamental até $3^{a}$ série do Ensino Médio de escolas públicas e particulares da cidade de São Paulo, chegaram à conclusão de que o trabalho apresenta-se como elemento central nos projetos de vida dos jovens, ou seja, o futuro é sempre relacionado a sua inserção na sociedade por meio de algum tipo de trabalho.

Bock e Liebsny (2003) chamam a atenção para o fato de que a ideologia liberal encontra-se fortemente presente entre esses jovens, que acreditam que cada um deve se esforçar para vencer na vida, e que esse esforço deve se voltar a uma direção voluntariamente escolhida. Acrescentam que poucos são os elementos críticos em relação ao trabalho, que aparece mais como emprego do que como contribuição social. Sinalizam, ainda, para o fato de que os jovens, independentemente da origem, se veem tendo concluído curso de nível superior em profissões clássicas (medicina, direito, engenharia etc.) nas quais possam obter sucesso.
Aguiar e Ozella (2003) também chamam atenção para a presença dessa crença entre os adolescentes das camadas populares, os quais acreditam que as dificuldades possam ser superadas pelo esforço pessoal. Consideram que

... o movimento que revelam, ao significarem sua escolha profissional, é, por um lado, o de apreender o peso das dificuldades econômicas, entendendo-as como um impedimento, e, por outro, o de buscar uma saída salvadora, o esforço pessoal, que aparentemente os liberta dessa armadilha, dessa situação quase sem saída (Aguiar \& Ozella, 2003, p.273).

Essa compreensão do futuro como resultante do esforço pessoal é também apontada por Andriani (2003), em estudo sobre o significado que o jovem negro escolar das classes populares constrói sobre sua escolha profissional. Em outra investigação, Oliveira, Sá, Fischer, Martins eTeixeira (2003) também observam que, na visão dos jovens de sua pesquisa, o esforço traduzido em estudo e trabalho determina o futuro, pois, em tese, pode assegurar uma melhor colocação profissional.

Assim, o futuro coloca-se como um ideal a ser conquistado em função da capacidade do adolescente. De acordo com Oliveira et al. (2003), esses adolescentes reconhecem as dificuldades de colocação no mercado de trabalho e atribuem à escolarização o diferencial de competitividade possível com os jovens de melhor formação. Apesar de caracterizada como "difícil", a realização das aspirações de sucesso profissional e financeiro apresenta-se como algo possível para os adolescentes, desde que ofereçam a sua contrapartida de investimento. Não são consideradas, pelos adolescentes estudados, quaisquer outras variáveis que não o esforço pessoal, afirmando uma relação de determinação de tipo unicausal, característica de uma apreciação moral do trabalho.

Esses adolescentes, como observam Sarriera, Cristina, Kabbas e Lópes (2001), acreditam que a via do trabalho é suficiente para acessar um outro patamar material e existencial. A inserção laboral significa o "passe de mágica" para esse futuro, que Ihes propiciará um negócio próprio, um emprego estável, uma boa qualidade de vida, um futuro condigno para eles e para seus familiares. Eles almejam, assim, encontrar na vida profissional a plena realização da identidade pessoal e ocupacional. 
Cassab (2001) alinha-se às posições anteriores, considerando que os desejos dos adolescentes das classes populares foram forjados no universo de uma sociedade salarial. A autora acrescenta que as imagens de futuro desses adolescentes estão circunscritas aos ideais da família nuclear burguesa, e que seu paradigma de felicidade se encontra assentado nos seguintes elementos: família estável, emprego estável, que dá dinheiro para viver. São poucos aqueles que expressam uma opção profissional, uma vez que essa não é uma escolha para eles (exceto alguns poucos), pois o trabalho é o que for possível, desde que ofereça boa remuneração e segurança.

De forma geral, esses autores consideram que os adolescentes das classes populares parecem não conseguir ressignificar os próprios sonhos e desejos como algo que se constitui também na relação com o mundo social. Apresenta-se, assim, uma perspectiva de se vencer magicamente uma realidade adversa, como uma espécie de vencedor que não fez nada de concreto para sê-lo.

Essa situação se agrava pelo fato de que no mercado formal de trabalho não há lugar para todos, o que configura um processo de exclusão, subcontratação e precarização do trabalho para muitos, e de inclusão para poucos. Pochmann (2000) chama atenção para essa problemática quando sublinha que o jovem, atualmente, só consegue trabalho em "bicos" ou estágios rápidos, nada que aponte para um futuro profissional ou uma estabilidade.

Por seu turno, Frigotto (2008) alerta para o fato de as políticas de formação profissional e de inserção de trabalhadores apagarem a perspectiva do coletivo e realçarem a competição individual. Assim, configura-se"nessas políticas, uma perspectiva estrita de adaptação aos objetivos do mercado e não aos direitos sociais dos trabalhadores e objetivos sociais mais amplos" (Frigotto 2008, p.1130).

Há, assim, conforme sinalizam Frigotto e Ciavatta (2006), uma regressão teórica e política, sob a ideologia neoliberal, focando os processos formativos dentro dos ideários do cidadão produtivo subordinado à lógica mercantil. Configura-se o desejo por um trabalhador flexível, que possua"as'competências' que se enquadram na lógica do 'cidadão produtivo' prontamente adaptá-

782 vel e que produz, em tempo mínimo, qualidade máxima e cuja mercadoria ou serviço se realizem no mercado imediatamente" (Frigotto \& Ciavatta, 2006, p.523).

O cenário justifica a pertinência desta pesquisa, com o objetivo de analisar o que os adolescentes e jovens esperam do futuro, a partir de sua vivência em programa de formação profissional alinhado à Lei de Aprendizagem.

\section{Método}

Participaram do estudo 16 adolescentes de ambos os sexos, sendo 9 matriculados no Curso de Serviços Administrativos do SENAC na cidade de João Pessoa (PB), e 7 egressos.

Para analisar o que os adolescentes aprendizes esperam do futuro, procedeu-se à pesquisa por meio de entrevistas individuais e coletivas de caráter semiestruturado. As questões norteadoras das entrevistas individuais contemplavam os seguintes aspectos: idade; sexo; escolaridade; o que deseja ser no futuro; e como a experiência no Programa pode ajudar a atingir essas expectativas em relação ao futuro.

Após aprovação pelo Comitê de Ética em Pesquisa do Centro de Ciências da Saúde da Universidade Federal da Paraíba, em sua 57a reunião ordinária, realizada no dia 23/03/2005, os pesquisadores responsáveis pelo estudo estabeleceram contato com o SENAC-JP e chegaram aos aprendizes. Após uma breve explanação acerca dos objetivos da pesquisa, eles foram informados da garantia de anonimato, sigilo e não obrigatoriedade em participar da pesquisa ou continuar até o final da entrevista.

Os aprendizes foram abordados no próprio SENAC ou no ambiente de trabalho, enquanto os egressos foram entrevistados no SENAC. Foram cumpridos todos os princípios éticos recomendados para pesquisas com seres humanos, tendo todos os adolescentes assinado o Termo de Consentimento Livre e Esclarecido antes da realização da entrevista.

As entrevistas individuais foram gravadas e depois transcritas, sendo a primeira versão fiel à fala do entrevistado. Em seguida, foi realizada uma leitura flutuante de todo o material e uma tabulação, que consistiu na agregação das temáticas semelhantes e posterior codificação, esclarecendo ao analista acerca das 
características do texto (Bardin, 1995). Dessa codificação emergiram as categorias representativas de cada temática, a saber: expectativas em relação ao futuro - "cursos de nível superior" e "trabalho de nível médio"; contribuição do Programa para a realização das expectativas em relação ao futuro - "vivência de experiência" e "disciplinamento" (sic).

A entrevista coletiva, agendada por telefone, aconteceu depois de analisadas as entrevistas individuais. Foram contatados os 16 adolescentes que participaram do estudo, dos quais 12 confirmaram presença e apenas 4 participaram (dois egressos e dois participantes do Programa). Nessa entrevista, procurou-se explorar os comentários que expressavam posições consensuais, contraditórias, ou mesmo singulares, funcionando como espaço de validação das interpretações e elaborações. A entrevista foi gravada e posteriormente transcrita para realização da análise de conteúdo temática.

\section{Resultados e Discussão}

Os 16 participantes da pesquisa apresentavam idade de 14 a 18 anos, sendo 9 do sexo feminino e 7 do masculino. Todos os entrevistados estudavam em escolas públicas, com escolaridade variando entre 8a série do ensino fundamental ao superior incompleto, predominando o $2^{\circ}$ ano do ensino médio.

Quando perguntados sobre o que desejavam ser no futuro, os adolescentes apontaram o que gostariam de ser profissionalmente. Fizeram referência a várias profissões, que podem ser agrupadas em duas categorias, "cursos de nível superior"e "trabalho de nível médio". Entre os adolescentes participantes do Programa, as duas categorias fizeram-se presentes com mesma representatividade, enquanto os egressos apresentaram leve predomínio da expectativa de trabalho de nível médio.

Entre os participantes do Programa, a categoria cursos de nível superior compreendia "odontologia", "ciências da computação", "enfermagem", "medicina" e "administração". Já, entre os egressos, a categoria cursos de nível superior compreendia "nutrição", "educação física", "engenharia mecânica", "administração" e "direito".

Quanto à categoria cursos de nível médio, para os participantes do Programa ela compreendia: "arqui- vagem" (Sic), "motorista de ônibus" e "recepcionista", ou seja, atividades que não promovem mobilidade nem ascensão socioeconômica, mas que podem garantir direitos trabalhistas, como carteira assinada, décimoterceiro salário, Fundo de Garantia pelo Tempo de Serviço (FGTS), entre outros direitos trabalhistas. Já para os egressos, compreendia: "trabalho em escritório", "trabalho no setor de pessoal", "policial" e "auxiliar de enfermagem". Portanto, sobressaem cursos relacionados ao tipo de formação que recebiam no SENAC, Serviços Administrativos.

Um curso superior, tanto para egressos como para participantes, é representado como garantia de inserção no mundo do trabalho, que, por sua vez, abre a possibilidade de ascensão socioeconômica. Resultados semelhantes também encontraram D'Avila et al. (2011) e Watarai e Romanelli (2010). Em relação à expectativa de um trabalho de nível médio, esse aparece condicionado à necessidade financeira dos adolescentes. A expectativa é representada não só pela garantia de sobrevivência, mas também como meio de, no futuro, conseguirem melhores oportunidades.

Essa busca pelo trabalho possível, desde que ofereça remuneração e o mínimo de segurança, também foi identificada por Cassab (2001) em seu estudo com adolescentes de classes populares. No estudo, os adolescentes desejavam um futuro assentado no binômio trabalho e família estável, paradigma de felicidade para eles. Poucos expressaram uma ocupação preferencial, pois o trabalho era o que se apresentasse possível, desde que tivesse boa remuneração e segurança, traduzido em garantias trabalhistas.

Os dados do estudo de Carpena (1999) vão na mesma direção, uma vez que 90\% dos entrevistados, quando questionados acerca do que desejavam ser no futuro, forneceram respostas ligadas à área profissional, seguidas de aspectos materiais, segurança ou bem-estar e aspectos afetivos. Desse modo, nas expectativas vislumbradas pelos adolescentes, tanto no estudo de Cassab (2001) quanto no de Carpena (1999), não há um rompimento claro com o modo de vida dos pais, nem o desejo de ascensão social.

Esse desejo aparece de forma bastante representativa entre os adolescentes aprendizes retratados neste artigo. No discurso da maioria dos sujeitos participantes da presente pesquisa, fica claro o desejo de 
ascender socioeconomicamente e de conseguir uma melhor inserção no mercado de trabalho, o que pode ser observado no depoimento de uma adolescente de 17 anos:

"... sinceramente eu prefiro estudar, tentar uma universidade porque quem trabalha no comércio vêque não énada fácil não, tem que ralar muito eéum trabalho que basicamentenãoéreconhecido....Émelhoragentetentar estudar pra ser alguém navida".

Igualmente, outra adolescente (16 anos) relata: Não quero coisa pesada não, quero um futuro melhor. Também o cara ter uma família e ganhar um salário- mínimo não dá não. Eu penso numa coisa grande.

Outro aspecto na presente pesquisa que chamou bastante a atenção foi o esforço pessoal como determinante do futuro. O relato desta adolescente de 16 anos aponta a questão:

"Assim, meu sonho mesmo era ser médica, sempre foi, desde criança. Não sei se eu vou conseguir estudar o suficiente para isso, claro, né? Tudo na vida tem que tero esforço, mas eu acredito queeu vou conseguir. Euvou, se eu colocar na cabeça mesmo".

Resultados semelhantes encontraram Oliveira et al. (2003), na medida em que os jovens abrangidos em seu estudo, apesar de caracterizarem como difícil a realização de determinadas aspirações de sucesso profissional e financeiro, entendem que elas poderão se concretizar, desde que eles ofereçam a sua contrapartida de investimento. Os autores acrescentam ainda que outras variáveis, que não o esforço pessoal, não são consideradas, o que pode ser entendido como uma característica da dimensão moral do trabalho. Resultados semelhantes também encontraram Andriani (2003), Aguiar e Ozella (2003), Bock e Liebsny (2003) e Carpena (1999).

Os dados empíricos sinalizam que essa percepção do futuro faz parte de uma subjetividade que emerge a partir de uma política de formação para o trabalho. Como mostra Frigotto (2008), no plano ideológico, desvia-se a responsabilidade do social para o individual, uma vez que, pelo fato de não haver políticas de emprego e renda dentro do projeto de desenvolvimento social nacional, considera-se que os adolescentes e jovens devam adquirir competências ou habilidades no campo cognitivo, técnico, de gestão e atitudes para

784 se tornarem competitivos e empregáveis. Para Frigotto
(2008), apenas terão chances aqueles que "se enquadrarem ao conjunto de competências técnicas, científicas, culturais e afetivas que o mercado reconhece como desejáveis do 'novo' cidadão produtivo" (Frigotto, 2008, p.525).

Nesse sentido, o formato das políticas para essa população constrói-se na indefinição de um lugar para ela no mercado de trabalho, haja vista as características do mercado flexibilizado, que requer um trabalhador "superqualificado", o que faz com que sua inserção fique comprometida. Esse fato se agrava quando essa política de formação consegue transferir a responsabilidade para essa população. Por outro lado, nas falas dos adolescentes, fica claro que eles internalizam essa transferência de responsabilidade, restando o Estado isento de toda responsabilidade diante do que vier acontecer em suas vidas. Portanto, se eles não conseguirem realizar seus sonhos, a culpa é única e exclusivamente deles próprios.

Uma vez que se fez presente, nas entrevistas individuais, tanto o desejo de os adolescentes continuarem trabalhando, quanto de cursarem uma faculdade, procurou-se questionar, na entrevista coletiva, como eles percebiam a relação trabalho/curso superior. As falas, tanto dos participantes quanto dos egressos, foram no sentido de perceber a possibilidade de conciliar as duas coisas e de visualizar o trabalho como um meio de financiar uma faculdade particular, validando assim os resultados obtidos nas entrevistas individuais e, de novo, ratificando o esforço pessoal como o elemento articulador entre trabalho e estudo, e como garantidor de futuro.

Tanto participantes como egressos, de fato, parecem não conseguir ressignificar os próprios sonhos e desejos. E, por não os analisarem criticamente, acabam por colocá-los num lugar especial e inquestionável, o que Alberto (2007) considera como uma expectativa da ordem do desejo. Por outro lado, há uma parte dos adolescentes deste estudo que vislumbra um futuro mais pautado na realidade, procurando realizar seus sonhos por intermédio dos estudos ou do trabalho e buscando formas de superar as adversidades do meio social.

Ao serem questionados sobre como a experiência no Programa de Aprendizagem poderia ajudá-los a realizar suas expectativas em relação ao futuro, tanto os participantes quanto os egressos destacaram as categorias: "vivência de experiência"e"disciplinamento"(sic). 
A categoria vivência de experiência denota que esses adolescentes esperam inserir-se no mercado de trabalho por terem experiência comprovada, obtendo carteira de trabalho assinada, em instituição nacionalmente reconhecida. Para os egressos entrevistados, todavia, isso continua se configurando como perspectiva - e não como dado real -, uma vez que eles não tinham conseguido se inserir no mercado de trabalho.

No que se refere ao "disciplinamento", os adolescentes consideraram que, por terem aprendido a respeitar, ouvir reclamações dos clientes sem questioná- los e moldar-se às exigências do mercado de trabalho, eles conseguiriam mais facilmente realizar seus sonhos.

Vale salientar que a inserção desses adolescentes no mundo do trabalho, por mais que esteja sendo intermediada por uma formação, como o coloca Frigotto (2007), não é uma escolha, mas, sim, imposição de uma realidade social excludente. Essa concepção é compartilhada também por Alberto (2007), ao ponderar que a inserção de crianças e adolescentes das classes populares no trabalho é pensada como uma forma de disciplinamento, prevenção à marginalidade e adestramento para o mundo do trabalho. Nesse sentido é que Cassab (2001) concebe o trabalho para adolescentes das classes populares como diferenciador da condição de "vagabundo".

Com o presente estudo pretendeu-se trabalhar com o adolescente concreto, conferindo-Ihe um caráter sócio-histórico. O interesse em obter um espaço no mercado de trabalho é bastante revelador das condições da adolescência de classe popular no contexto da formação profissional, tornando patentes os seus problemas e os códigos que lhe servem de suporte para enfrentar os conflitos.

De acordo com Baptista (2004), um estudo realizado pela Secretaria de Formação e Desenvolvimento Profissional (SEFOR), no Rio de Janeiro, constatou que 75\% dos adolescentes egressos da qualificação profissional ficaram em situação inalterada, enquanto apenas 21\% passaram a receber mais, e 5\% passaram a receber menos. O autor observa ainda que $73 \%$ dos entrevistados não consideram que as mudanças tenham se dado em razão do curso.

Nas entrevistas coletivas, foi retomada a questão sobre a forma como o Programa poderia ajudar os adolescentes a realizar suas expectativas em relação ao futuro. As falas acompanharam o que emergiu nas entrevistas individuais, ou seja, validaram as categorias "vivência de experiência" e "disciplinamento".

Outro aspecto tratado na entrevista coletiva foi a percepção de que o Programa não ajudaria a realizar os sonhos. As falas dos adolescentes, porém, procuraram desqualificar esse ponto de vista, com o argumento de que, se eles "realmente fossem atrás, iriam conseguir". Mais uma vez aparece aqui a dimensão do esforço pessoal, que está relacionada tanto com uma concepção liberal de homem, quanto com uma dimensão moral do trabalho (Andriani, 2003; Oliveira et al., 2003).

Os dados identificados na pesquisa também corroboram as observações de Frigotto (2008), que, ao analisar as propostas de formação profissional, considera que elas se amoldam a uma lógica unidimensional mercantil e se fundamentam na ideia de que é o indivíduo o responsável por seu sucesso ou insucesso.

Chamou atenção o fato de que participantes e egressos não diferem, em muito, naquilo que esperam para o futuro. Há apenas um leve predomínio da expectativa de trabalho de nível médio por parte dos egressos, enquanto entre os participantes do Programa predominou a expectativa de formação superior. Isso pode ser explicado tanto pelo fato de os adolescentes egressos terem saído há pouco tempo do Programa, quanto pelo fato de não terem, ainda, conseguido inserirse no mercado de trabalho, começando, assim, a apresentar uma expectativa da ordem da realidade, em que há maiores reflexos da necessidade imediata do que dos sonhos.

\section{Considerações Finais}

A constituição desses adolescentes reflete-se em suas expectativas em relação ao futuro, o que possibilita pensar na subjetividade como fabricada e modelada através desse dispositivo institucional - Programa de Formação Profissional, que se incumbe de banalizar a vida, reduzindo-a ao trabalho, ou seja, adestrando tais sujeitos ao mundo do trabalho.

Emerge, dessa forma, uma subjetividade engendrada como "resíduo", no processo de produção de uma sociedade modelada sob a lógica do capital. Assim, esses adolescentes parecem não conseguir ressignificar os 
próprios sonhos e desejos, nem perceber que estes se constituem, também, na relação com o mundo social. E, por não os analisarem criticamente, acabam por colocá-los num lugar especial e inquestionável.

Por outro lado, alguns adolescentes deste estudo vislumbram um futuro mais pautado na realidade, na medida em que procuram realizar seus sonhos por intermédio dos estudos ou do trabalho e buscam formas de superar as adversidades do meio social. Nesse sentido, o Programa de Aprendizagem propicia um aspecto que acende, em boa parte dos adolescentes, o desejo de continuar os estudos até o nível superior. Mas, por outro lado, o Programa não propicia elementos para uma análise crítica, de forma que esses adolescentes não têm clareza de que a realização de seu sonho não depende apenas do esforço pessoal e que nem mesmo a formação profissional, por uma instituição reconhecida, é garantidora. Ela pode ser apenas uma ferramenta no jogo dos esforços profissionais.

Percebe-se, assim, uma subjetividade modelada sob a lógica do capital. Ao serem adestrados ao mundo do trabalho, os sujeitos internalizam uma concepção liberal de homem, que os culpabiliza por sua exclusão ou seu insucesso, escamoteando as causas estruturais desse processo.

\section{Referências}

Aguiar, F. H. R., \& Conceição, M. I. G. (2009). Expectativas de futuro e escolha vocacional em estudantes na transição para o ensino médio. Revista de Orientação Profissional, 10 (2), 107-117.

Aguiar, W. M. J., \& Ozella, S. (2003). O sentido subjetivo atribuído à escolha profissional: um estudo com jovens de camadas populares. In S. Ozella (Org.), Adolescências construídas: a visão da psicologia sócio-histórica (pp.253-276). São Paulo: Cortez.

Alberto, M. F. P. (2007). As implicações psicossociais do trabalho precoce de meninos e meninas em condição de rua. Laboreal, 3 (2), 8-21.

Andriani, A. G. P. (2003). O significado construído por jovens negros pertencentes a camadas populares sobre a escolha do futuro profissional. In S. Ozella (Org.), Adolescências construídas: a visão da psicologia sócio-histórica. (pp.223-252). São Paulo: Cortez.

Baptista, T. A. (2004). O jovem trabalhador brasileiro e qualificação profissional: a ilusão do primeiro emprego. In M. A. Sales, M. C. Matos \& M. A. Leal (Orgs.), Política social, família e juventude: uma questão de direito (pp.131-146). São Paulo: Cortez.
Bardin, L. (1995). Análise de conteúdo. Lisboa: Edições 70.

Bock, A. M. B., \& Liebesny, B. (2003). Quem eu quero ser quando crescer: um estudo sobre o projeto de vida de jovens em São Paulo. In S. Ozella (Org.), Adolescência construída: a visão da psicologia sócio-histórica (pp.203222). São Paulo: Cortez.

Bock, A. M. B., \& Liebesny, B. (2007). Adolescência como construção social: estudo sobre livros destinados a pais e educadores (PEE - 319). Psicologia Escolar e Educacional, 11 (1), 63-76.

Brasil. (2005, 15 de junho). Medida Provisória, no 251 de 14 de junho de 2005 (pp.4). Diário Oficial da União, Seção 1.

Carpena, M. (1999). Famílias de meninosemeninas em situação de rua na cidade de Caxias do Sul: locus de controle, situação atual de vida e expectativas para o futuro. Dissertação de mestrado não-publicada, Curso de Pós-Graduação em Psicologia do Desenvolvimento, Universidade Federal do Rio Grande do Sul, Porto Alegre.

Carvalho, R. G., Pocinho, M., \& Silva, C. (2010). Comportamento adaptativo e perspectivação do futuro: algumas evidências nos contextos da educação e da saúde. Psicologia: Reflexão e Crítica, 23 (3), 554-561.

Cassab, M. A. T. (2001). Jovens pobres e o futuro: a construção da subjetividade na instabilidade e incerteza. Niterói: Intertexto.

Costa, M., \& Guedes, R. (2009). Expectativas de futuro como efeito-escola: explorando posibilidades. São Paulo em Perspectiva, 23 (1), 101-114

D'Avila, G. T., Krawulski, E., Veriguine, N. R., \& Soares, D. H. P. (2011). Acesso ao ensino superior e o projeto de "ser alguém" para vestibulandos de um cursinho popular. Psicologia \& Sociedade, 23 (2), 350-358.

Da Silva, V. H. (2011). Cidadania e inserção laboral assistida: a experiencia de trabalho formal de adolescentes pobres. Estudos de Psicologia (Natal), 16 (2), 187-196.

Frigotto, G. (2007). A relação da educação profissional e tecnológica com a universalização da educação básica. Educação e Sociedade, 28 (100), 1129-1152.

Frigotto, G. (2008). Educação profissional e capitalismo dependente: o enigma da falta e sobra de profissionais qualificados. Trabalho Educação e Saúde, 3 (5), 521-536.

Frigotto, G., \& Ciavatta, M. (2006). A formação do cidadão produtivo: a cultura do mercado no ensino médio técnico. Brasília: Inep.

Jacobina, O. P., \& Costa, L. F. (2007). "Para não ser bandido": adolescentes em conflito com a lei e trabalho. Cadernos de Psicologia e Sociologia do Trabalho, 2 (10), 95-110.

Lima, S. M. (2006). Os aprendizes das ruas e a tríade educação, trabalho e cidadania. Psicologia Ciência eProfissão, 1 (26), 106-117.

Locatelli, A. C. D., Bzuneck, J. A., \& Guimarães, S. É. R. (2007). A motivação de adolescentes em relação com a perspectiva de tempo futuro. Psicologia Reflexão e Critica, 2 (20), 268-276.

Matheus, T.C. (2003). O discurso adolescente numa sociedade na virada do século. Psicologia USP, 14 (1), 85-94. 
Nunes, M. F. O., \& Noronha, A. P. P. (2011). Associações entre auto-eficácia para atividades ocupacionais e interesses em adolescentes. Psicologia: Reflexão e Crítica, 24 (1), 1-9.

Oliveira, D. C., Sá, C. P., Fischer, F. M., Martins, I. S., \& Teixeira, L. R. (2003). Futuro e liberdade: o trabalho e a instituição escolar nas representações sociais de adolescentes. Estudos de Psicologia, 6 (1), 245-258.

Pochmann, M. (2000). A batalha pelo primeiro emprego: as perspectivas e a situação atual do jovem no mercado de trabalho. São Paulo: Publisher Brasil.

Sarriera, J. C., Silva, M. A., Kabbas, C.P., \& Lopes, V. B. (2001). Formação da identidade ocupacional em adolescentes. Estudos de Psicologia (Natal), 6 (1), 27-32.

Sartori, F. A., Noronha, A. P. P., \& Nunes, M. F. O. (2009). Comparações entre EAP e SDS: Interesses profissionais em alunos de Ensino Médio. Boletim de Psicologia, 59 (130), 17-29.
Sposito, M. P., \& Corrochano, M. C. (2005). A face oculta da transferência de renda para jovens no Brasil. Tempo Social, Revista de Sociologia da USP, 7 (2), 141-172.

Wagner, A., Falcke, D., \& Meza, E. B. D. (1997). Crenças e valores dos adolescentes acerca de família, casamento, separação e projetos de vida. Psicologia: Reflexão e Crítica, $10(1), 157-169$

Watarai, F., \& Romanelli, G. (2010). Adolescentes do sexo masculino: trabalho remunerado e construção da identidade. Psicologia em Estudo, 15 (3), 547-556.

Wickert, L. F. (2006). Desemprego e juventude: jovens em busca do primeiro emprego. Psicologia Ciência eProfissão, 2 (26), 258-269.

Recebido em: 12/3/2012

Aprovado em: 23/4/2012 
